\begin{tabular}{l} 
Published as: Azadi, H., D. Samari, K. Zarafshani, G.H. \\
Hosseininia \& F. Witlox (2013) Sustainable forest \\
management in Iran: A factor analysis. Sustainability \\
Science. Vol. 8 (4), pp. 543-551. \\
\hline
\end{tabular}

\title{
Sustainable Forest Management in Iran:
}

\author{
A Factor Analysis \\ Hossein Azadi ${ }^{\mathrm{a} 1}$, Davood Samari ${ }^{\mathrm{b}}$, Kiumarz Zarafshani ${ }^{\mathrm{c}}$, \\ Gholamhossein Hosseininia $^{\mathrm{d}}$, Frank Witlox ${ }^{\mathrm{a}}$ \\ ${ }^{a}$ Department of Geography, Ghent University, Belgium. \\ ${ }^{b}$ Department of Agricultural Extension and Education, Garmsar Branch, \\ Islamic Azad University, Semnan, Iran. \\ ${ }^{c}$ Agricultural Extension and Rural Development, Razi University, Kermanshah, Iran. \\ ${ }^{d}$ Department of Entrepreneurship Extension \& Education, Tehran University, Iran.
}

\begin{abstract}
Since 1996, several Forest Resources Management Plans (FRMPs) have been launched by the Iranian government in order to approach sustainable forest management in the Zagros area in west and south-west Iran. This survey study aimed at providing some policy recommendations in order to launch more successful FRMPs. Using a proportional cluster random sampling method, the data were collected from 208 forestdwellers (beneficiaries) and 90 practitioners. The results showed that the FRMPs are far from being satisfactory. There are several reasons for this failure. First, the financial resources allocated to these plans are being used for other purposes. Second, the inputs and supplies needed for effective forest management interventions are not in place in a

\footnotetext{
${ }^{1}$ Corresponding author. Email: hossein.azadi@ugent.be, Phone: +32 (0)9 26446 95, Fax: +32 (0)9 264 4985.
} 
timely manner. Third, the forest management in the area is far from being decentralized. Both the beneficiaries and practitioners believe that the forest-dwellers play a weak role in the forest management interventions. Factor analysis revealed that three factors which are influencing the Zagros management effectiveness are "the management capabilities of the forest-dwellers", "the professional capabilities of the practitioners in forest management", and "the public support for the forest-dwellers". Also, the correlation analysis revealed that all the three factors are positively and significantly associated with the success of the government's forestry programs. Accordingly, the main recommendation of this study was to reformulate the forest management policies in the Zagros area by highlighting participatory approaches, not only as a tool, but also as a goal in the FRMPs.

Keywords Forestry · Sustainable forest management · Participation · Factor analysis · Human factor $\cdot$ Zagros

\section{Introduction}

Sustainable forest management (SFM) depends mostly on implementing a set of principles that include environmental, socio-economic, and political aspects. Low socioeconomic status within forest communities may not only destabilize the equilibrium between vegetative cover and stocking rate $^{2}$ at regional level, but may indirectly result in climate change at global level. The destructive behaviour of forest communities in Iran is a good example of the impact of such a low status can have.

\footnotetext{
${ }^{2}$ Stocking rate is expressed as the number of animal units per month supplied by one hectare of land (Azadi et al 2007).
} 
Literature highlights the benefits of forests for forest-dwellers. For example, Amani (2000), Olivet (1999) and Jom`a Pour (1999) argue that forest resources fulfil socioeconomic, ecological, cultural, and psychological needs of both present and future generations. In addition, Lakany and Hosny (2000) remind that the Food and Agriculture Organization (FAO) of United Nations regards forestry as a global objective because it plays a crucial role in socio-economic advancement, environmental sustainability, and maintaining and improving sustainable use of natural resources. Interestingly, due to another report by FAO (2001), many governmental and nongovernmental agencies have promoted and institutionalized SFM at different regional, national, and international levels. However, to approach SFM, the following requirements should be met: supporting the key stakeholders of forest resources; participating different stakeholders in forest management process, including the beneficiaries of forest resources; establishing a strong planning sector on the basis of advanced methodologies for appraising forest resources; strengthening forestry institutes; supporting forest-dwellers; and finally convincing national and international agencies to perform their role more effectively in relation to SFM.

Toha and Barros (1997) discuss that a practical sustainable forest intervention is subjected to five prerequisites: 1) the availability of information and resources on forest management; 2) a continuous production process; 3) environmental controls; 4) the provision of appropriate institutional structures; and 5) socio-economic considerations. Shaditalab (1998) believes that although all the prerequisites are proposed to be universally workable, the socio-economic aspect may differ from one country to another. In the view of relevant experts, this aspect should be considered as the most important prerequisite. Furthermore, a number of environmental experts and 
practitioners have also come to this conclusion that the socio-economic dimension in modern forest management is a new crucial challenge, especially in developing countries. Interactions among the prerequisites and their impacts are shown in Fig. 1.

[Insert Fig. 1 here]

The main management activities (conservation and restoration) of forests and natural resources in Iran are largely in the hands of the central government. It is therefore imperative to focus on the role of government, when analysing forest management strategies in the country. Accordingly, the government is responsible for five different functions in the national forest management, which are namely "policy-making", "implementing", "controlling", "supporting", and "guiding". Fig. 2 illustrates the interactions between the functions in forest management strategies implemented by the Iranian government.

[Insert Fig. 2 here]

\section{Forest management in Zagros}

One of the main Iranian forest areas is Zagros. The Zagros area spans the western and south-western length of the Iranian plateau and ends at the Straits of Hormuz. It is over $1300 \mathrm{~km}^{2}$ and also covers 12 provinces (Azerbaijan Gharbi, Kurdistan, Kermanshah, Eilam, Lorestan, Chaharmahal-Bakhtiari, Fars, Isfahan, Khuzestan, KohgilouyehBoyerahmad, Hamedan, and Markazi). Classified as a semi-arid forest region with an area of 5 million ha, the Zagros area includes $40 \%$ of the national forests (Fig. 3).

[Insert Fig. 3 here] 
According to the Iranian Statistics Centre (1996), the area contains 83 townships and more than 19,200 villages, nearly $30 \%$ of the total population and covers some $25 \%$ of total national area. More than $70 \%$ of the Iranian nomads live in this area, which includes around $50 \%$ of the livestock population; i.e. approximately $63,142,000$ heads. At the national level, the area is appreciated as the top producer of wheat and forage in the country. In addition, it plays a significant role in the national economy because of the abundance of oil fields, minerals, ecotourism, apiculture, water resources and production of herbal medicines associated with aquaculture.

Considering the importance of the Zagros area as one of the major forest resources in the country, since 1996, the Forest, Range, \& Watershed Management Organization (FRWMO) in Iran has launched several forest conservation and restoration intervention programs ${ }^{3}$ in order to develop the 'community forestry approach'. By promoting the active participation of the forest-dwellers, the approach aims not only to 'protect', 'restore', and 'develop', but also to govern the sustainable 'use' of the forests.

The intervention programs mostly include Forest Resources Management Plans (FRMPs) that aim at enhancing sustainable forest management. As reported by IRNA (2011), an area about $1,569,338$ ha was surveyed ${ }^{4}$ in the Zagros area through the FRMPs, of which some 458,267 ha had been carried out by the executive agents (in this study the forest-dweller and practitioners) of the plans.

These conservational interventions fall into two major classifications: a) bio-physical processes; and b) socio-economic issues. The former studies include physiographic, topography, meteorology, climatology, geology, geo-morphology, resource assessment,

\footnotetext{
${ }^{3}$ The programs include those interventions, which aim at approaching sustainable forest management by enhancing both the forest conservation and utilization in the long-run.

${ }^{4}$ The surveys are a part of feasibility studies, which are necessarily being conducted before launching any FRMP.
} 
land use development, pedology, hydrology, soil erosion and sediments, forests, utilization of by-products, and the wildlife. The latter focus on the 'human factor', relating to training, extension service, and grassroots participation.

\section{Objectives and hypotheses}

In line with the socio-economic studies, this survey is an attempt to seek some recommendations for the Iranian forestry directorates with the hope to bring more sustainable forest management into the Zagros area. More precisely, this study tries: i) to understand the forest-dwellers and practitioners' agreement with the forest management practices implemented by the government; ii) to comprehend the interrelationships among the practices; and iii) to determine the relationship between forest management factors and the extension activities as the main government interventions ${ }^{5}$ to approach SFM.

Accordingly, the following hypotheses are assumed ${ }^{6}$ :

a) There is a positive significant correlation between the managerial capabilities of the forest-dwellers and the extension activities.

b) There is a positive significant correlation between the professional capabilities of the practitioners and the extension activities.

c) There is a positive significant correlation between public support of the forestdwellers and the extension activities.

\footnotetext{
5 According to the Forest Research Division of the Iranian Research Institute of Forest and Rangelands (RIFR 2010), the interventions are mainly oriented to improve the following activities: "conservation, restoration, utilization, and development" of the forests.

6 The main reason to assume these hypotheses was to understand whether the training, extension, and grassroots participation factors can govern the continuality of extension activities as the main 'government forest interventions'.
} 


\section{Methodology}

The population of this study consisted of two different groups: a) the forest-dwellers $(\mathrm{N}=6255)^{7}$; and $\left.\mathrm{b}\right)$ the practitioners $(\mathrm{N}=90)$. The former are the residents who live in the sites where the FRMPs are implemented. The latter includes those experts and managers who are involved in the FRMPs' managerial team such as directors, technical assistants, extension managers, forestry, and utilization offices. To draw a representative sample, one province was randomly selected in each region (North, Centre, and South) of the Zagros area. The selected provinces were Kurdistan (Northern Zagros), Ilam (Central Zagros), and Fars (Southern Zagros). Because the provinces were not exhaustive, a proportional cluster random sampling method (Levy and Lemeshow 2009) was used to select the dwellers. Using Cochran's formula (equation 1), 208 respondents were selected for the study. Due to the limited number of the practitioners, census sampling was used to obtain the data.

Where:

$$
\mathrm{n} \frac{\mathrm{N}(\mathrm{t} \mathrm{s})^{2}}{\mathrm{Nd}^{2}+(\mathrm{t} \mathrm{s})^{2}}=208 \quad \text { (equation 1) }
$$

$$
\begin{aligned}
& \mathrm{n}=\text { sample } \\
& \mathrm{N}=\text { population }(1782)^{8} \\
& \mathrm{t}=\mathrm{t} \text {-student }(\mathrm{t}=1.96 ; \text { prob. }=0.95) \\
& \mathrm{s}=\text { standard deviation of } 30 \text { respondents in the pilot study }(0.94) \\
& \mathrm{d}=\text { preferred likelihood accuracy }{ }^{9}(0.12)
\end{aligned}
$$

\footnotetext{
${ }^{7}$ The total number of forest-dwellers in the country.

${ }^{8}$ The total number of forest-dwellers in the selected provinces.

${ }^{9}$ The expert recommendation was $10 \%$ (which is the common level for a desired precision in the country) while a slightly more precision $(12 \%)$ was considered.
} 
In order to make a proper distribution of the sample in the selected provinces, the elicited sample was drawn on each province proportionally as shown in the equations 24:

- $\quad$ Kurdistan: $n_{k}=N_{k} \times n / N=49.4 \simeq 49$

- $\quad$ Ilam: $\mathrm{n}_{\mathrm{i}}=\mathrm{N}_{\mathrm{i}} \times \mathrm{n} / \mathrm{N}=59.5 \simeq 60$

- $\quad$ Fars: $\mathrm{n}_{\mathrm{f}}=\mathrm{N}_{\mathrm{f}} \times \mathrm{n} / \mathrm{N}=99.1 \simeq 99$ (equation 2)

(equation 3)

(equation 4)

A researcher-made questionnaire was used to collect data from the dwellers and practitioners. A pilot study was conducted to measure the reliability of the questionnaire: 30 questionnaires were filled out by both the beneficiaries (forestdwellers) and the practitioners in Hamedan province. Cronbach's alpha coefficient was estimated at 0.87 , which indicates that the questionnaire has a high internal consistency (Cronbach 1951; Nunnally and Bernstein 1994; Streiner 2003).

Beside quantitative measurements, a qualitative study was held by conducting two focus group interviews with some key informants. The interviewees consisted of two groups of informants (i.e., eight key forest beneficiaries and nine key forest practitioners) who were purposefully selected through a 'typical case sampling' (Patton, 2002). Using Nvivo 9, the qualitative data were further investigated and content-analyzed. Finally, using a mixed-method approach (Tashakkori and Teddlie 2003), some qualitative data were used as confirmatory information for quantitative data in order to make a data triangulation.

\section{Results and discussion}


The beneficiaries and practitioners were asked to express their level of agreement with the forest management practices implemented by the government in the Zagros area. A total of 24 forest management practices were asked from both the beneficiaries and practitioners. Although the beneficiaries rank the current practices from "low" to "medium", they feel that the FRMPs' supervisors are somewhat responsible for the forest management practices $(M=3.41)^{10}$. However, the practitioners rank this factor as their second priority $(\mathrm{M}=3.44)$. In other words, they do not feel that the supervisors are adequately responsible for their supervisory task. They also rank the managers' willingness to provide the opportunities for the forest-dwellers to participate in forest management as their first priority $(\mathrm{M}=3.51)$. However, this factor is ranked in the third place $(M=3.32)$ by the beneficiaries. Providing the forest-dwellers with needed inputs was ranked in the second place $(\mathrm{M}=3.34)$ by the beneficiaries whereas this particular factor was selected as the fifth priority $(\mathrm{M}=3.23)$ by the practitioners.

In general, both the beneficiaries and practitioners ranked none of the 24 management practices as "very high" or "high". The current state of some of the forest management practices conducted by the government such as "focussing on the subsistence needs of the forest-dwellers", "generating employment opportunities through establishing small industries around the sites", "creating communication networks for dissemination of research findings within the forestry community", and "taking into consideration the ecological sustainability" are ranked as "low" by the beneficiaries, who have ranked other practices not more than "medium". Likewise, the practitioners perceived "creating communication networks for dissemination of research findings within the forestry community" as "medium" and the other forest management practices as "low".

[Insert Table 1 here]

${ }^{10} \mathrm{M}$ : mean rank 
It is assumed that the variance of each measurement could be decomposed into common and unique portions. Thus, a "factor analysis" was applied. Such an analysis is especially recommended when the measured variables are assumed to be a linear function of the unmeasured (covert) variables. Since the analysis was drawn on the sample rather than the population, maximum likelihood factor analysis with varimax rotation was considered appropriate (Costello and Osborne, 2005).

Only those factors with eigenvalues equal to or greater than 1.0 were considered in the analysis. In addition, a scree plot of the eigenvalues was used to identify the breaks or discontinuities in determining the number of factors. The two procedures resulted in identification of three factors underlying the status of forest management in the Zagros area.

The factors were labelled as (1) public supports for the forest-dwellers (2) managerial capabilities of the forest-dwellers in forest management (3) professional capabilities of the practitioners in forest management. The three factors accounted for approximately $57.3 \%$ of the variance of the 'optimal forest management' variable (Table 2).

[Insert Table 2 here]

The last objective of this paper was to determine the relationship between the forest management factors and the government forest interventions. As shown in Table 3, Spearman correlation coefficient reveals that there is a positive and significant relation between the forest management predictors and the government forest interventions. In other words, when the managerial capabilities of the forest-dwellers increase; conservation, restoration, utilization, and development aspects of the forest intervention 
also increase. It also means when the forest-dwellers are managing the forests more effectively, they are more able to conserve, restore, utilize, and develop the forests. This is also true for professional capabilities of the practitioners in forest management. When this capability increases, likelihood of the forestry intervention success also increases. Public support for the forest-dwellers seems to have a strong association with the government forest interventions. When the level of this support increases, the forestdwellers are more motivated to conserve, restore, utilize, and develop the forests.

[Insert Table 3 here] 
According to the results, the FRMPs launched by the Iranian government are far from being satisfactory. In this regard, three issues seem to be important. The first is the FRMPs' supervisors and their loyalty toward the forest management interventions. How responsible they are towards what is proposed in their plans as the main objectives of the FRMPs (i.e. conserving, restoring, utilizing and developing) in the Zagros forests. If they are indeed responsible, why inputs and other essential supplies are not reaching to the forest-dwellers in a timely manner. The qualitative results obtained from focus group interviews show that the financial resources allocated to the FRMPs are being used for other purposes:

“I know some of the FRMPs' supervisors who bought personal cars out of the loan even though they may not spend the loan on activities other than the FRMPs' objectives. This mainly happens because of the weak monitoring system", said one of the forest practitioners who participated in the focus group.

Whatever their intentions might be, one thing is clear: the needed inputs are not there at the right time and place. Therefore, the second issue is that the inputs and supplies needed for effective forest management interventions are not timely in place, which in turn, shows a mismanagement of these resources. Third, the result of this empirical study indicated that forest management in Iran is far from being decentralized.

Factor analysis revealed that three factors: the management capabilities of the forestdwellers, the professional capabilities of the practitioners in forest management, and the public support for the forest-dwellers are influencing the Zagros management effectiveness. As pointed out earlier, participatory methods and approaches in forest 
management are rather ineffective in the Zagros area. This, in turn, would provide limited opportunity for the forest-dwellers to become empowered in managing the Zagros forests. Accordingly, when dealing with forest-dwellers, the human factor is poorly understood. Furthermore, the forestry directorates do not provide the forest practitioners with the participatory methods and the required resources for dealing with forest dwellers at the right time.

Moreover, the forest practitioners are not efficacious enough at managing the forest. This can be explained by the fact that the practitioners realize that their job is not wellappreciated by the public. For example, the so-called "forest keepers" in Iran are finding their job more hazardous than before because of armed forest wood smugglers:

"People often don't respect us as forest-keepers, despite the fact that we have a hard job; sometimes we have to fight against forest wood smugglers", said one of the forest keepers who participated in the focus group.

This has created very limited prospects for potential forestry practitioners. This, in turn, has led to fewer skilled and well-educated people being attracted to government-based forest business. In addition, a lack of private sector forest programs in Iran has demotivated public sector forestry to attract competent individuals into non-competitive forestry programs.

The factor analysis further showed that the forest-dwellers' tasks are not being appreciated by the public. Although the Iranian government has continuously reminded people that natural resource conservation should be part of the Iranian culture, the forest-dwellers are still alone in their endeavour in forest conservation, restoration, utilization, and development. This lack of public support often arises from a lack of 
awareness of the issues in individual lives related to the value and worth of natural resources in general, and forestry in particular.

Finally, the correlation analysis revealed that all three factors mentioned above are positively and significantly correlated with the government's forestry programs. This implies that the more efficacious the forest-dwellers and practitioners act (in forest management), the more effective the forest interventions (conservation, restoration, utilization, and development) would be.

\section{Conclusion}

Many range and forest management experts (Azadi et al 2007; 2009; Samari et al 2012) in Iran have come to believe that government-based interventions in the Zagros area are ineffective with regard to the human factor. This line of thinking has motivated Iran's forestry directorates to propose participatory methods to approach sustainability in forest management in general, and in the Zagros area in particular. Yet, both the beneficiaries and practitioners believe that the forest-dwellers play a weak role in the forest management interventions. It seems that the Zagros forestry practitioners are using participatory methods and approaches only to receive financial resources from national and international donors without any real participation by the forest-dwellers. This is "facipulation" rather than participation. The term facipulation consists of 'facilitation' and 'manipulation' (Botes and van Rensburg 2000) in the sense that the practitioner consciously directs the efforts toward an objectively desirable goal (Constantino-David 1982). In other words, facipulation is manipulative facilitation that serves the process of facilitation in favour of facilitator rather than serving the receiver or participant. In the case of Zagros, facipulation takes place when the forest directorates pretend to believe in participation, while in reality, when it comes to forest 
practitioners' interventions, this is not the case. For any true participation, there are prerequisites that need to be addressed when making policies and plans. A major prerequisite is that the Zagros forest policy-makers need to bring the last first and the first last (Chambers 1997). However, it is not that difficult to bring the last (beneficiaries) first, but it is difficult to put the first (practitioners) last. Most forest elites do not like to be placed last and therefore forest-dwellers miss the opportunity to raise their voice and participate in the forest management interventions, thus their valuable indigenous knowledge is not used effectively.

The above discussions bring us to two practical recommendations: i) participatory forest management should come to the core forest policies and plans; not only as a tool, but also as a goal in the FRMPs. Such approaches, to be applicable, should begin with the forest-dwellers. In other words, their indigenous knowledge, as well as experiences, should form the basis for any interventions; and ii) avoid facipulation in every way and make the participation of the forest-dwellers real by bringing them from the last to the first. In other words, and according to Chambers (1997), the practitioners should try to "hand over the stick" and take the role of a listener or learner, and if they have a problem with that; they must at least, try to get "hold of the other end of the stick" and act more like a catalysts or facilitators.

\section{Acknowledgment}

The authors wish to thank Dr. Mairtin McNamara and Ms. Lena Bigelow for improving the English of the text. 


\section{References}

Amani M (2000) The national forestry plan (National Action). Forest and Range Magazine 48:12-17 [in Persian]

Azadi H, Shahvali M, van den Berg J, Faghih N (2007) Sustainable rangeland management using a multi-fuzzy model: how to deal with heterogeneous experts' knowledge. Journal of Environmental Management 83:236-249

Azadi H, van den Berg J, Shahvali M, Hosseininia G (2009) Sustainable rangeland management using fuzzy logic: a case study in Southwest Iran. Agriculture, Ecosystems \& Environment 131:193-200

Botes L, van Rensburg D (2000) Community participation in development: nine plagues and twelve commandments. Community Development Journal 35:41-58

Chambers R (1997) Whose reality counts? Intermediate Technology Publications. Bath Press, London

Constantino-David K (1982) Issues in community organization. Community Development Journal 17:190-201

Costello AB, Osborne JW (2005) Best practices in exploratory factor analysis: four recommendations for getting the most from your analysis. Practical Assessment Research \& Evaluation 10:1-9

Cronbach LJ (1951) Coefficient alpha and the internal structure of tests. Psychometrika $16: 297-334$

FAO (2001) State of the world forest. FAO, Rome

Iranian Statistics Centre (1996) National statistics yearbook. Tehran, Iranian Statistics Centre [in Persian] 
Jom'a Pour M (1999) Sustainable development and the role of popular participation in managing optimized and sustainable use of natural resources. Proceedings of First Congress on Natural Resources, Participation, and Development. Tehran, Ministry of Agriculture [in Persian]

Khalyani AH, Falkowski MJ, Mayer AL (2012) Classification of Landsat images based on spectral and topographic variables for land-cover change detection in Zagros forests. International Journal of Remote Sensing 33:6956-6974

Lakany E, Hosny L (2000) Strategic plan for forestry. FAO, Rome

Levy PS, Lemeshow S (2009) Sampling of populations: methods and applications $\left(4^{\text {th }}\right.$ edition). New York, John Wiley \& Sons

Nunnally JC, Bernstein IH (1994) Psychometric theory (3rd ed.). New York, McGraw Hill

IRNA (2011) An overview of Forest Resources Management Plans in the north of Iran Available on: http://www2.irna.ir/ar/news/view/line-14/8907259963145459.htm [in Persian]

Olivet AJ (1999) An introduction to sustainable development in developing countries. Translated version published by Rural Development Institute Publisher, Tehran Patton MQ (2002) Qualitative research \& evaluation methods ( $3^{\text {rd }}$ ed.). Thousand Oaks, CA, Sage Publications

RIFR (2010) Annual report. Forest Research Division. Research Institute of Forest and Rangelands, Tehran [in Persian]

Samari D, Azadi H, Zarafshani K, Hosseininia G, Witlox F (2012) Determining appropriate forestry extension model in the Zagros area, Iran: Application of AHP. Forest Policy and Economics 15:91-97 
Shaditalab J (1998) Community forestry. A research plan. Social Science College, Tehran University [in Persian]

Streiner D (2003) Starting at the beginning: an introduction to coefficient alpha and internal consistency. Journal of Personality Assessment 80:99-103

Tashakkori A, Teddlie C (2003) Handbook of mixed methods in social \&. behavioral research. Thousand Oaks, CA, Sage

Toha GJ, Barros A (1997) The role of forest policies and institutes in achieving sustainable forest development. Unasylva 48:190-191 


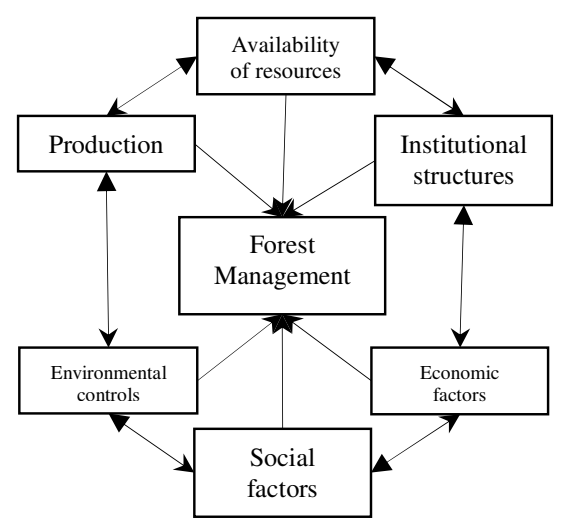

Fig. 1 A theoretical scheme for sustainable forest management (adapted from Shaditalab 1998) 


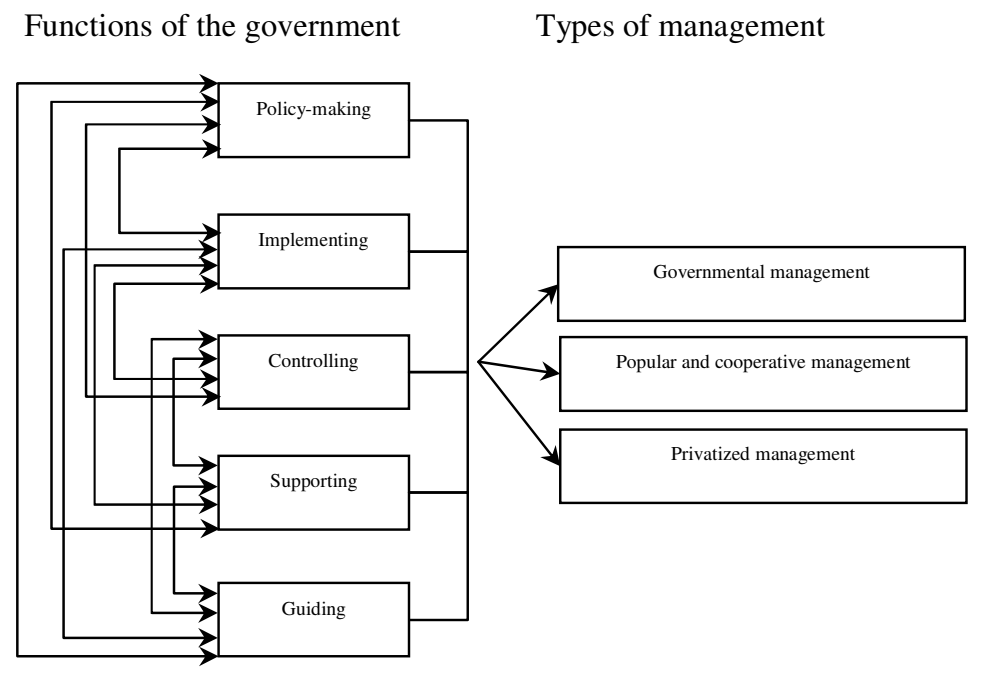

Fig. 2 The role of government in managing forests and the way they interact to determine different types of forest management strategies (adapted from Shaditalab 1998) 


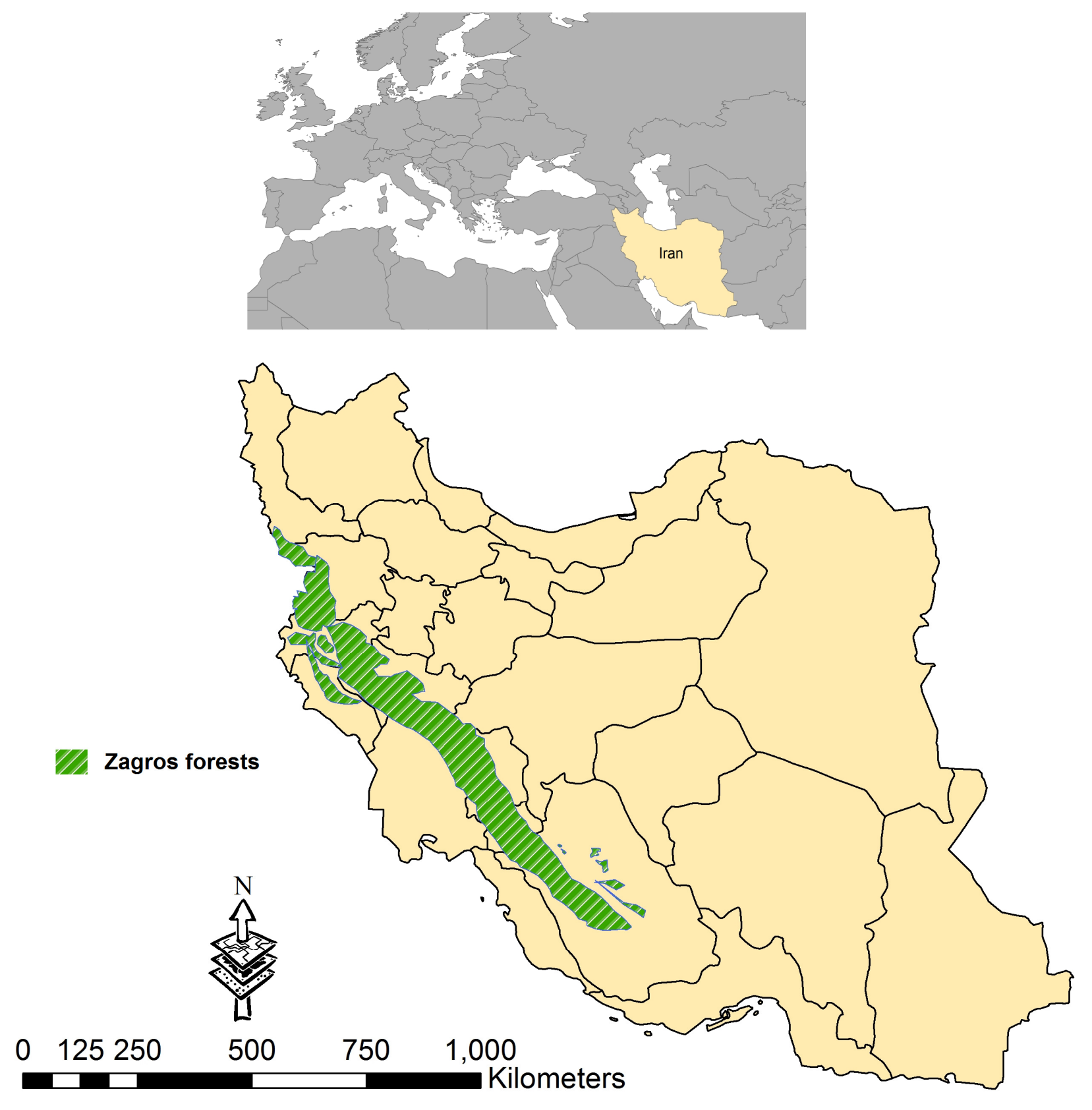

Fig. 3 The study area

(adapted from Khalyani et al 2012) 
Table 1 The extent to which beneficiaries and practitioners perceive current forest management practices satisfactory

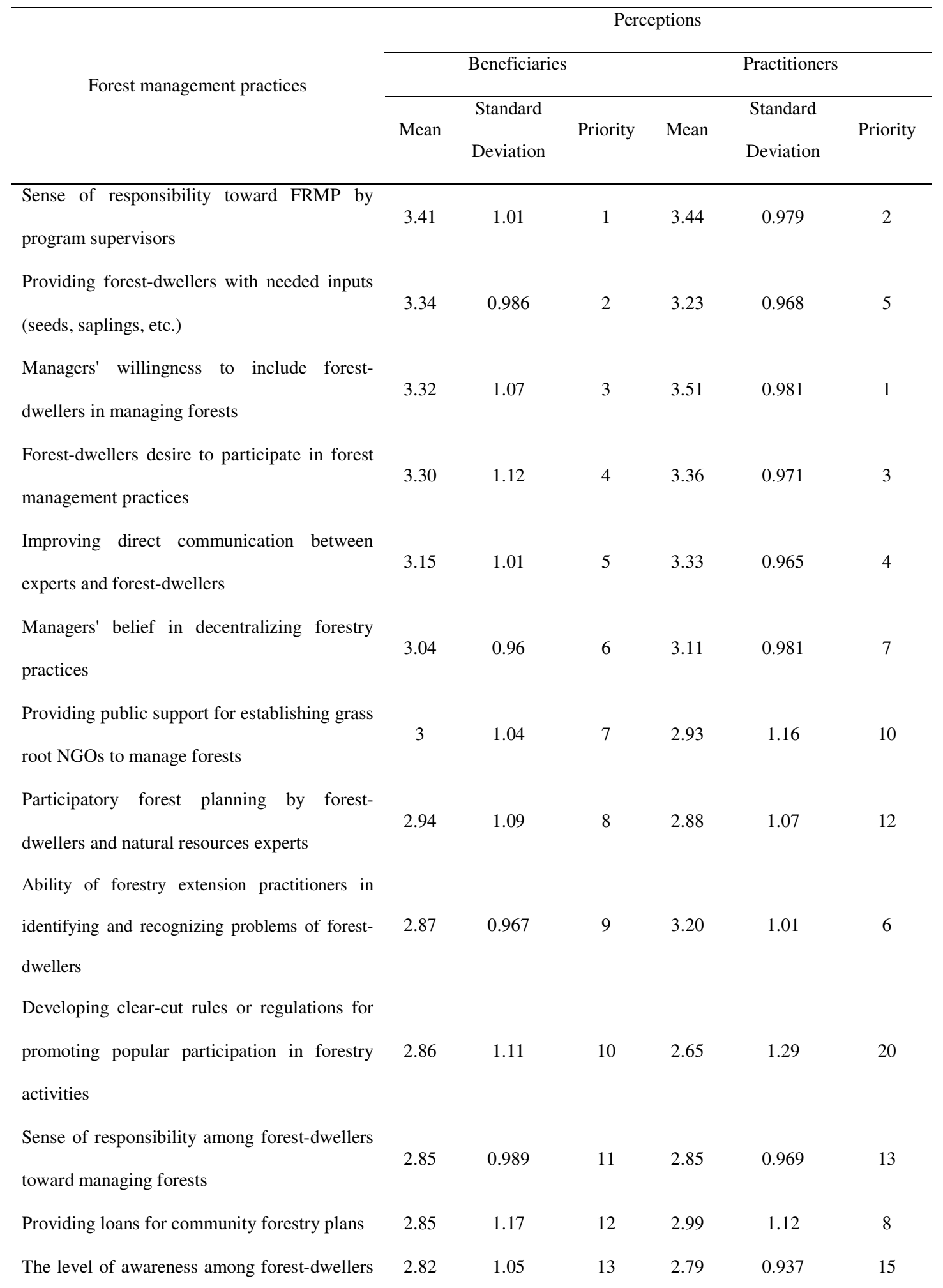


about the need for managing forests

Controlling forest-dwelling population

2.81

1.13

Conducting integrated forestry extension

programs

Providing forest-dwellers with information about forest issues

Recognizing potentials forest-dwellers

1.07

1.15

2.60

research

Allocating public financial resources needed

for community forestry programs

Utilizing indigenous knowledge of forest-

dwellers in forest management practices

2.54

1.13

19

2.78

1.10

17

$$
2.50
$$

1.06

20

2.74

1.18

19

Creating communication networks for

dissemination of research findings on

2.47

1.20

21

2.38

1.18

24

community forestry

Focussing on the subsistence needs of forest-

dwellers

$\begin{array}{llllll}2.42 & 1.10 & 22 & 2.90 & 1.30 & 11\end{array}$

Consideration the ecological sustainability

1.17

$23 \quad 2.84$

1.14

14

Generating employment around forests

2.33

1.27

$24 \quad 2.51$

1.24

23

and ( 5 = very high agreement) 
Table 2 Factor loading matrix*

\begin{tabular}{|c|c|c|c|c|}
\hline \multirow{2}{*}{ No. } & \multirow{2}{*}{ Variables } & \multicolumn{3}{|c|}{ Factor } \\
\hline & & $1^{\mathrm{a}}$ & $2^{b}$ & $3^{\mathrm{c}}$ \\
\hline 1 & $\begin{array}{l}\text { The awareness level of forest-dwellers about the need } \\
\text { for managing forests }\end{array}$ & 0.52 & 0.58 & \\
\hline 2 & $\begin{array}{l}\text { Responsibility sense of forest-dwellers toward } \\
\text { managing forests }\end{array}$ & 0.50 & 0.63 & \\
\hline 3 & $\begin{array}{l}\text { Providing forest-dwellers with information about } \\
\text { forest issues }\end{array}$ & 0.67 & 0.21 & -0.25 \\
\hline 4 & Recognizing technical potentials of forest-dwellers & 0.65 & 0.32 & \\
\hline 5 & $\begin{array}{l}\text { Taking into consideration the indigenous knowledge } \\
\text { of forest-dwellers in forestry projects }\end{array}$ & 0.70 & & \\
\hline 6 & $\begin{array}{l}\text { Focussing on the subsistence needs of the forest- } \\
\text { dwellers }\end{array}$ & 0.73 & & -0.20 \\
\hline 7 & Interest of forest-dwellers in managing forests & 0.55 & 0.42 & 0.28 \\
\hline 8 & $\begin{array}{l}\text { Managers' desire for participation of forest-dwellers } \\
\text { in managing forests }\end{array}$ & 0.55 & & 0.42 \\
\hline 9 & Responsibility sense of the supervisors of FRMPs & 0.48 & & 0.54 \\
\hline 10 & $\begin{array}{l}\text { Improving direct communication between experts } \\
\text { and forest-dwellers }\end{array}$ & 0.54 & & 0.33 \\
\hline 11 & Performing relevant community forestry studies & 0.73 & & \\
\hline 12 & Conducting integrated forestry extension programs & 0.70 & -0.22 & \\
\hline 13 & $\begin{array}{l}\text { Generating employment opportunities through } \\
\text { establishing small industries around the forests }\end{array}$ & 0.78 & & \\
\hline 14 & $\begin{array}{l}\text { Developing clear cut rules or laws for promoting } \\
\text { popular participation in forestry activities }\end{array}$ & 0.71 & -0.27 & \\
\hline 15 & $\begin{array}{l}\text { Providing public supports for establishing grassroots } \\
\text { NGOs to manage forests }\end{array}$ & 0.61 & -0.21 & 0.39 \\
\hline 16 & $\begin{array}{l}\text { Creating communication networks for dissemination } \\
\text { of research findings on community forestry }\end{array}$ & 0.78 & -0.24 & \\
\hline 17 & $\begin{array}{l}\text { Participatory planning of forestry activities by } \\
\text { forest-dwellers and natural resource experts }\end{array}$ & 0.74 & & \\
\hline
\end{tabular}




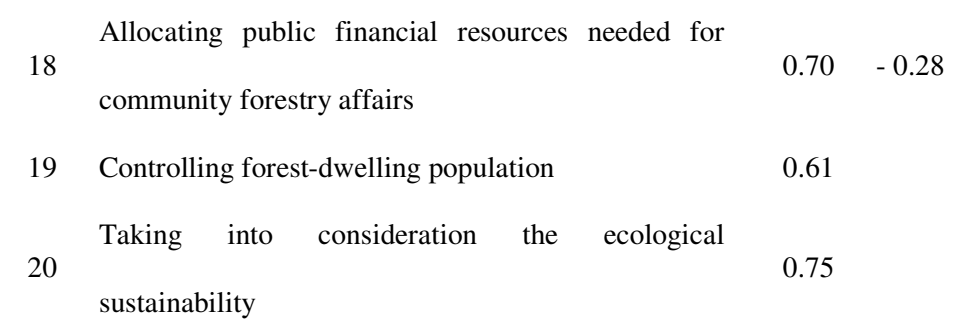

* The coefficients less than $(0.20)$ are not reported.

${ }^{\text {a }}$ Factor 1: Public supports for the forest-dwellers $($ Eigenvalue $=8.76)$.

${ }^{\mathrm{b}}$ Factor 2: Managerial capabilities of the forest-dwellers in forest management $($ Eigenvalue $=1.56)$.

${ }^{\mathrm{c}}$ Factor 3: Professional capabilities of the practitioners in forest management $($ Eigenvalue $=1.14)$. 
Table 3 The correlation coefficients (r) between forest management factors and government forest interventions

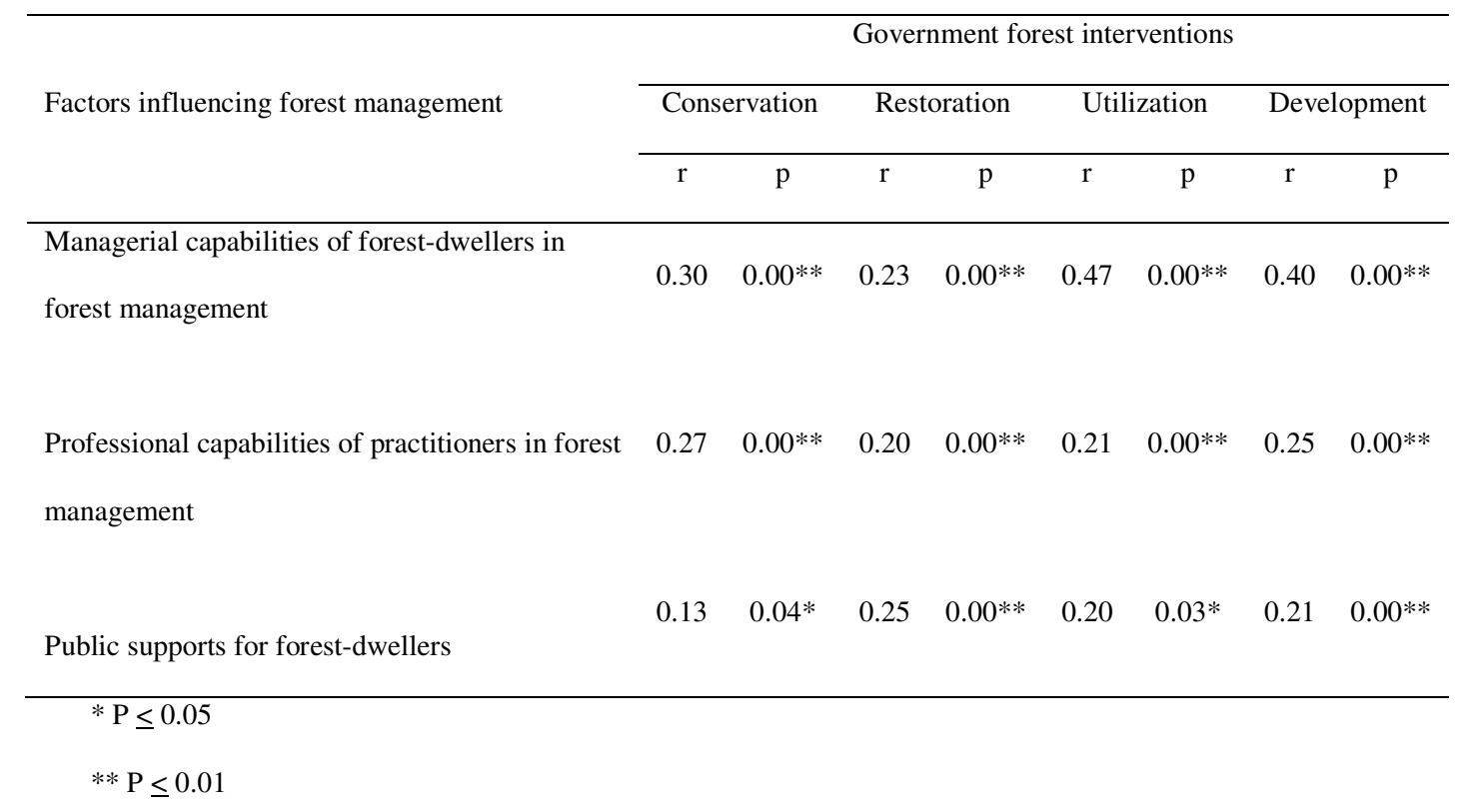

